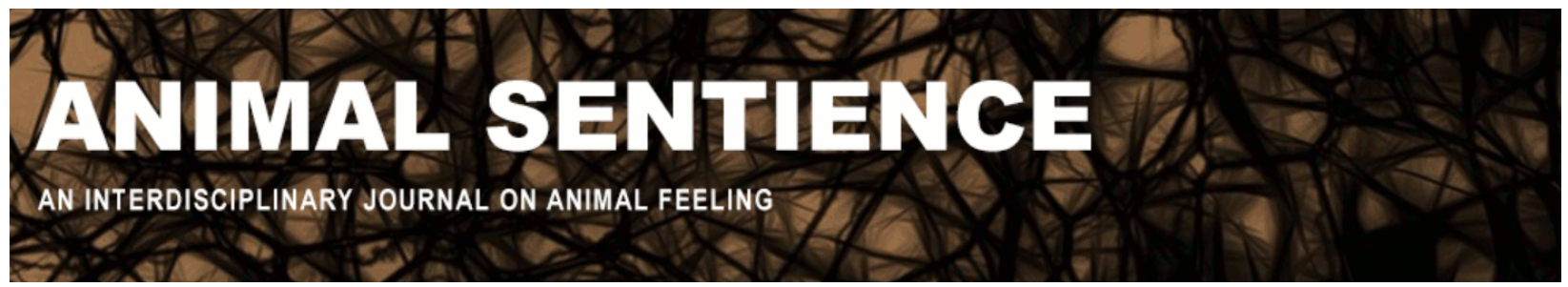

Harnad, Stevan (2016) My orgasms cannot be traded off against others' agony. Animal Sentience 7(18)

DOI: $10.51291 / 2377-7478.1118$

Date of submission: 2016-06-28

Date of acceptance: 2016-07-06

(c)

This article has appeared in the journal Animal

Sentience, a peer-reviewed journal on animal

cognition and feeling. It has been made open access,

free for all, by WellBeing International and deposited

in the WBI Studies Repository. For more information,

please contact

wbisr-info@wellbeingintl.org.

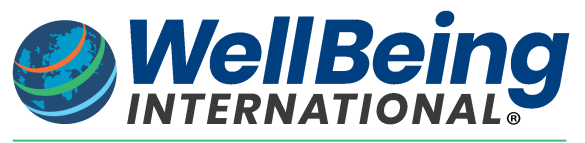

SOLUTIONS FOR PEOPLE, ANIMALS AND ENVIRONMENT 


\title{
My orgasms cannot be traded off against others' agony
}

Commentary on $\mathrm{Ng}$ on Animal Suffering

\author{
Stevan Harnad \\ Cognitive Sciences Institute \\ Université du Québec à Montréal
}

\begin{abstract}
Only I can calculate my own welfare as net pleasure minus pain. No one else can do that calculation for me - nor for a population, and especially not averaging across some individuals' pleasure and other individuals' pain. Pain and pleasure are incommensurable and only pain matters morally. To maximize welfare is to minimize pain.
\end{abstract}

Stevan Harnad is Professor of cognitive science at Université du Québec à Montréal and University of Southampton. His research is on category learning, language evolution, consciousness, and open access. Founder and former editor of the journal Behavioral and Brain Sciences, Harnad is becoming increasingly active in the problems of animal welfare, animal rights and animal

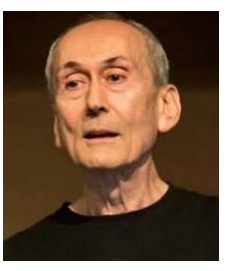
law. http://bit.ly/StevanHarnadUQÀM

Unipolar and bipolar continua. Subjective continua, like other continua, come in at least two forms: (1) a unipolar intensity continuum like perceived loudness of sound (Stevens 1936) ranges from zero intensity to maximal intensity; (2) a bipolar intensity continuum like perceived temperature has a midpoint that is perceived as neither hot nor cold, situated between two opposite unipolar continua, going from zero to maximal intensity heat in one direction and from zero to maximal intensity coldness in the other (Gescheider 2013). (There may also be other changes along a sensory continuum: Beyond a certain threshold level, increasing loudness and heat are perceived as also becoming increasingly painful, but psychophysical testing is usually restricted to levels below the unpleasant range.)

In the perceived temperature continuum, increasing heat does not feel like decreasing coldness. Heat and cold are perceived as qualitatively different, like two different unipolar continua, not a mixture of the two qualities, as in the blue-green spectral region of the bipolar blue/green wave-length continuum. The mid-point of hot/cold feels like zero in both qualities, whereas the midpoint of blue/green feels like a mixture, half-blue and half-green, with the blue/green ratio increasing on one side of this midpoint and decreasing on the other.

The hedonic continuum. The pleasure/pain continuum (Bartoshuk 2014) is bipolar, like hot/cold, with a zero midpoint. This is unlike either a unipolar intensity continuum such as loudness or a bipolar ratio continuum such as blue/green. Pain and pleasure differ in quality: one is affectively positive and one is affectively negative. They are otherwise incommensurable 
(except perhaps in comparing the relative size of increases or decreases in each quality). For this reason, it makes no sense to add and subtract across both half lines to integrate "net" welfare over both these qualities. To put it another way, orgasms cannot be traded off against agony. I can do it for myself, deciding how many lashes I would personally endure in exchange for how many orgasms. But no one else can judge that for me; I doubt that any two individuals would agree on their personal trade-offs. Most important, there is no way to trade off my orgasms against others' agony in some sort of integrated net pain/pleasure formula purporting to maximize net welfare for a population.

Maximizing pleasure vs. minimizing pain. It follows that if welfare comparisons or integrations are to be applied across multiple individuals, it can only be done separately for pain and separately for pleasure. Moreover, if it weren't for the empirical fact that being deprived of pleasure can itself feel painful, just as being deprived of food does, it is not clear whether happiness (Kahneman et al. 1999) would be a welfare matter at all - or at least whether it would be a moral matter (rather than merely a hedonic one).

Consider first that in a world consisting exclusively of insentient organisms - Darwinian robots that survive, reproduce, adapt and learn, just like us, but without feeling a thing, positive or negative - there would clearly be no such thing as positive or negative welfare: no morality. Nothing would matter. Even in our own world, it is the partial coupling of pleasure with pain (because pleasure reduction or deprivation can also feel painful) that makes pleasure matter morally at all. For in a unipolar hedonic world with only pleasure and no pain (hence no regret or disappointment or discomfort if deprived of pleasure) there would be no welfare problems to speak of either. What happens in a world of pleasure zombies is as morally irrelevant as what happens in a world of insentient zombies or a world of rocks. Utilitarian calculations (orgasm counts) would be mere hedonic numerology.

What this implies is that it is really only pain (suffering) that matters. Hence the only welfare calculations that matter are the ones that minimize pain, factoring in pleasure only to the extent that being deprived of pleasure may sometimes be painful.

Moral perfection. It is not clear that the ideal of everyone's treating all sentient beings equally from one's firstborn to a flea - would be viable in our biosphere, with its conflicts of vital (i.e., survival) interests (Harnad 2007). It would mean mammalian parents not nurturing or favouring their own offspring, complete impartiality toward kin and kind, ally and competitor, friend and foe, perhaps even self and other. If utter selfishness, indifferent to the costs of our orgasms in the agony of others, is psychopathic, so too would be utter selflessness, resolving all conflicts of interest with a utilitarian toss of the coin. But just following the imperfect welfare principle that "if the vital interests of you and yours are met, maximize the vital interests of the others" would already be enough to turn most of us in the luckier parts of the world into vegans today, and many of the luckiest ones into welfare activists on behalf of all sentient beings (Harnad 2014).

Pain and probability. Let me close on the subject of probability and uncertainty in inferring whether another being feels at all (and if so, whether and how much it suffers): This is the 
classical other-minds problem (Harnad 2016). But in the context of animal welfare it is not just the philosopher's epistemic uncertainty (which, as $\mathrm{Ng}$ notes, applies equally to other human beings, even when they are telling you what they are feeling) that is at issue. For me, based on my data, the probability that you feel may be infinitesimally small. But for you, if you do feel, and I mistakenly infer (and treat you as if) you do not, there is nothing that matters more. In other words, the other-minds problem is not our problem, but the other mind's problem. Decency dictates that - within the scope of what is practically possible - we give the other mind the benefit of the doubt.

\section{References}

Bartoshuk, L. (2014). The measurement of pleasure and pain. Perspectives on Psychological Science, 9(1), 91-93.

Gescheider, G. A. (2013). Psychophysics: The fundamentals. Psychology Press.

Harnad, S. (2007). Evan. In: Vilarroya, O. \& Forn, F., Social Brain Matters: Stances on the Neurobiology of Social Cognition. Editions Rodopi, Amsterdam/New York, http://eprints.ecs.soton.ac.uk/10703/01/huma-evan.html.

Harnad, S. (2014). Animal pain and human pleasure: Ethical dilemmas outside the classroom. LSE Impact Blog, June 13, 2014.

Harnad, S. (2016) Animal sentience: The other-minds problem. Animal Sentience 2016.001.

Kahneman, D., Diener, E., \& Schwarz, N. (Eds.). (1999). Well-being: Foundations of hedonic psychology. Russell Sage Foundation.

$\mathrm{Ng}$, Y-K. (2016). How welfare biology and commonsense may help to reduce animal suffering. Animal Sentience 2016.007.

Stevens, S. S. (1936). A scale for the measurement of a psychological magnitude: Loudness. Psychological Review, 43(5), 405. 